\title{
Sustentabilidade e educação ambiental: um destaque aos resíduos sólidos gerados assentamento Santo Antônio - Paraíba - Brasil
}

Os progressos da humanidade contribuíram para melhorar a qualidade e a expectativa de vida, mas, em contrapartida, o consumismo compromete o bem-estar das gerações futuras e do meio ambiente, visto que ocasiona crescimento na geração de resíduos e de dejetos. Neste sentido, a Educação Ambiental é um processo que busca despertar a preocupação individual e coletiva que impulsam ações que visem a sustentabilidade ambiental. Este cenário motivou a construção deste trabalho, cujo objetivo geral foi analisa o modo de vida no Assentamento Santo Antônio, localizado no município de Cajazeiras, estado da Paraíba, Nordeste do Brasil. Assim, os procedimentos adotados pautaramse no levantamento de dados primários, mas também, no levantamento bibliográfico, bem como, na estruturação de ações educativas voltadas para a sustentabilidade, disseminando e coordenando atividades ligadas à gestão ambiental, mais específico, aos resíduos sólidos, no que concerne à geração de renda, recursos naturais, qualidade de vida e a própria relação destes humanos com a natureza. Para tanto, foram realizadas palestras, oficinas, e cartilha sobre compostagem, biodigestor e a implantação do sistema de coleta seletiva que tiveram a finalidade de contribuir com a melhoria da produção, alimentação e renda da comunidade. No que tange os resultados verificou-se que os tipos e condições de moradia, foram observados que os habitantes do assentamento em estudo, possuem residência de alvenaria (90\%), seguido de madeira, e materia reciclado. No que concerne à utilização de qualquer tipo de fontes energéticas no assentamento, estes fazem uso apenas de energia elétrica, não citando outro modo de energia alternativa sustentável, a exemplo do biogás proveniente de biodigestor. Por outro lado, quanto ao aproveitamento de algum tipo de material que iria ser descartado o plástico tem sido um dos mais reutilizados por $75 \%$ dos assentados, seguido de pouco mais de $8 \%$ dos moradores que reaproveitam papel, vidro e metal. Provocados a respeito da possibilidade dos seus trabalhos gerarem danos ao meio ambiente $75 \%$ disseram que sim, ou seja, e, $25 \%$ dos entrevistados afirmaram que o seu trabalho não causa danos para a natureza. Concluiu-se então que a proposta de educação em constante diálogo com a natureza representou um resgate de conhecimentos locais favoráveis ao desenvolvimento de práticas de valorização dos recursos naturais, assim como os saberes locais podem ser articulados pela educação ambiental e modificar os modos de viver e compreender a natureza, seus limites, desafios e impedimentos, com um olhar de quem está inserido no ambiente, experimentando suas mutações e resistências às condições naturais.

\section{Sustainability and environmental education: a highlight of solid waste generated Santo Antônio setting - Paraíba-Brazil}

\begin{abstract}
The progress of humanity has contributed to improve the quality and life expectancy, but, on the other hand, the consumerism compromises the well-being of future generations and the environment, since it causes growth in waste generation. In this sense, environmental education is a process that seeks to awaken the individual and collective concerns that motivate actions aimed at environmental sustainability. Thus, the adopted procedures followed primary data collection, but also, bibliographic survey, as well on structuring educational activities aimed at sustainability, disseminating and coordinating activities related to environmental management, more specific, solid waste with regard to income generation, natural resources, quality of life and the relationship of these with human nature. To this end, lectures, workshops, and manual on composting, digester and the implementation of selective rubish collection which had the purpose of contributing to the improvement of production, food and community income. Regarding the results, it was verified that the types and conditions of living, were observed that the inhabitants of the settlement, have masonry residence (90\%), followed by wood, and recycled material. With regard to the use of any type of energy sources in the settlement, these make use only of electricity, citing not otherwise sustainable alternative energy e.g. biogas from biodigester. On the other hand, regarding to the use of any type of material that would be thrown, the plastic has been one of the most re-used by $75 \%$ of the settlers, followed by just over $8 \%$ of residents who recycle paper, glass and metal. Provoked regarding the possibility of their work generate damage to environment, $75 \%$ said yes, i.e. $25 \%$ of respondents stated that your jobs does not cause damage to the nature. It was concluded then that the proposal to education in constant dialogue with nature represented a development-friendly local knowledge of natural resources development practices, as well as local knowledge can be articulated by the environmental education and change the ways of living and understanding the nature, its limits, challenges and impediments, with a look of who is included in the environment, experiencing their mutations and resistance to natural conditions.
\end{abstract}

Keywords: Natural Conditions; Natural Resources; Humanity.

Topic: Educação Ambiental

Reviewed anonymously in the process of blind peer

Eclivaneide Caldas de Abreu Carolino

Universidade Federal de Campina Grande, Brasil

http://lattes.cnpq.br/2505704671466878

eclivaneide@hotmail.com

Roberlucia Araújo Candeia

Universidade Federal da Paraíba, Brasil

http://lattes.cnpq.br/3402528767552686

roberlucia.candeia@ccta.ufcg.edu.br

Ricelia Maria Marinho Sales

Universidade Federal de Campina Grande, Brasil

http://lattes.cnpq.br/4718608750713388

ricelia_marinho@ccta.ufcg.edu.br

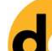

DOI: $10.6008 / S P C 2179-6858.2017 .004 .0018$
Received: 16/07/2017

Approved: 17/10/2017

\author{
Camilo Allyson Simões de Farias \\ Ehime University, Japão \\ http://lattes.cnpq.br/7482889323422305 \\ camiloallyson@yahoo.com.br \\ Eliezer da Cunha Siqueira \\ Universidade Federal de Campina Grande, Brasil \\ http://lattes.cnpq.br/5420335048712215 \\ eliezer.siqueira@ifpb.edu.br
}

Referencing this:

CAROLINO, E. C. A.; CANDEIA, R. A.; SALES, R. M. M.; FARIAS, C. A. S. SIQUEIRA, E. C.. Sustentabilidade e educação ambiental: um destaque aos resíduos sólidos gerados assentamento Santo Antônio - Paraíba Brasil. Revista Ibero-Americana de Ciências Ambientais, v.8, n.4 p.210-229, 2017. DOI: http://doi.org/10.6008/SPC21796858.2017 .004 .0018 


\section{INTRODUÇÃO}

A Educação Ambiental é um processo que busca despertar a preocupação individual e coletiva para a questão ambiental, bem como o acesso à informação em linguagem adequada, contribuindo para o desenvolvimento de uma consciência crítica e estimulando o enfretamento das questões ambientais e sociais. Desenvolve-se em um contexto de complexidade, procurando trabalhar não apenas a mudança cultural, mas também a transformação social, assumindo a crise ambiental como uma questão ética e política (MOUSINHO, 2003).

O processo de Educação Ambiental divide-se em duas categorias básicas: educação formal e educação informal. A primeira envolve estudantes em geral, desde a educação infantil até a fundamental, média e universitária, além de professores e demais profissionais envolvidos em cursos de treinamento em Educação Ambiental; já a segunda envolve todos os segmentos da população, como, por exemplo, grupos de mulheres, jovens, trabalhadores, políticos, empresários, associações de moradores, profissionais liberais, dentre outros (MARCATTO, 2002).

As preocupações com o meio ambiente impõem novas estratégias de vida, em virtude de uma série de problemas globais, tais como contaminação e degradação do ambiente, a crise de recursos naturais, energéticos e de alimentos (BILGEN, 2014). Tais problemas resultam da alta taxa de crescimento populacional, devido ao aumento da utilização excessiva e desordenada dos recursos do planeta. De todo modo, o consumo exacerbado dos recursos oriundos das reservas naturais proporciona a degradação progressiva dos solos, poluindo o ar atmosférico e afetando as condições de regeneração dos ecossistemas (MAIA, 2011).

Os progressos da humanidade contribuíram para melhorar a qualidade e a expectativa de vida, mas, em contrapartida, o consumismo compromete o bem-estar das gerações futuras e do meio ambiente, visto que ocasiona crescimento na geração de resíduos e de dejetos. Esse compromisso com as gerações futuras é o princípio do que se denomina crescimento sustentável. Portanto, espera-se que haja políticas públicas viáveis que possam auxiliar na convivência do ser humano com a natureza, propondo uma transformação de matérias já utilizadas para uma forma de reaproveitamento sustentável (GUERRA, 2012).

Os resíduos sólidos, quando destinados de forma inadequada produzem grandes impactos ambientais, causando poluição das águas superficiais e subterrâneas, contaminação dos solos e do ar e a proliferação de doenças; não constituem somente um problema de ordem estética, mas representa também uma séria ameaça à espécie humana e ao meio ambiente, diminuindo consideravelmente os espaços úteis disponíveis (TENÓRIO et al., 2004; SCHALCH et al., 2002).

Ao serem destinados adequadamente apresentam extrema importância no que se refere à qualidade de vida dos indivíduos na sociedade, e redução aos riscos à saúde pública. Sabe-se que o tratamento nunca constitui um sistema de destinação final completo ou definitivo, pois sempre há um remanescente inaproveitável, mas, as vantagens decorrentes dessas ações, tornam-se mais claras após o equacionamento dos sistemas de manejo e de destinação final dos resíduos (GUERRA, 2012). 
A Associação Brasileira de Empresas de Limpeza Pública e Resíduos Especiais (ABRELPE), em 2013 publicou informações sobre a gestão de resíduos sólidos urbanos (RSU) e de serviços de saúde (RSS) nas regiões brasileiras, e confirmou prejuízos ambientais e econômicos gerados por manejos inadequados. A referida pesquisa limitou-se apenas a 404 Municípios na qual se evidenciou que a geração de resíduos urbanos em todo o país obteve total de 209.280ton/dia, compreendendo uma população de 201.062 .789 habitantes. Isto representa um aumento de $4,1 \%$ em relação ao índice da taxa de crescimento populacional no Brasil que atingiu no ano de 2013 de 3,7\%.

Constam nesses dados que a destinação inadequada de RSU se faz presente em todas as regiões e estados brasileiros e 3.344 municípios, correspondentes a 60,0\% do total, ainda fizeram uso em 2013 de locais impróprios para destinação final dos resíduos coletados. No concernente à região Nordeste, a situação da destinação final destes resíduos revela ser crítica, tendo observado que dos resíduos coletados na região cerca de $65 \%$ correspondente a 27.116 toneladas por dia são destinados aos lixões e aterros controlados. Percebendo-se que esses não diferenciam dos próprios lixões a céu aberto, pois não possuem o conjunto de sistemas necessários para proteção do meio ambiente e da saúde pública (ABRELPE, 2015).

Assim, os resíduos sólidos apresentam-se como uma questão complexa, necessitando de políticas públicas e manejos adequados para sua destinação final. No entanto, sabe-se pouco sobre a sua disposição em áreas rurais, principalmente nos assentamentos. Sabe-se que quando são depositados de forma incorreta nas propriedades rurais causam diversos problemas de ordem ambiental, tais como: poluição do solo, da água e do ar trazendo consigo problemas relacionados à agricultura, considerando que esses resíduos sólidos provocam o surgimento de vetores de diversas doenças.

Tratando-se do ambiente rural, objeto desta pesquisa, percebeu-se que a população do Assentamento Rural Santo Antônio/PB, queimava o resíduo produzido, quando parte do material poderia ser reaproveitado. Esses resíduos passíveis de reaproveitamento poderiam tornar-se uma fonte de renda para contribuir com o orçamento familiar, por meio da confecção e venda do artesanato. Além da possibilidade de parte deles, serem reintroduzidos no processo de produção agrícola, como biofertilizantes.

Nessa perspectiva, formulou-se a seguinte problemática: Por meio da educação ambiental trabalhada sob a forma de pesquisa-ação é possível melhorar a qualidade de vida dos assentados e contribuir com a diminuição dos impactos ambientais causados por aquela população?. Este trabalho contemplou a questão da educação ambiental na zona rural a partir dos assentados, ou seja, com aqueles que lidam diariamente no campo, expostos a riscos de contaminação por efluentes, agrotóxicos e outras fontes. A forma de abordagem foi através de encontros, reuniões e workshop sobre a coleta seletiva, biodigestão anaeróbia, compostagem e reaproveitamento de resíduos sólidos domésticos para confecção de artesanato.

O principal objetivo foi contribuir por meio de ações educativas voltadas para a sustentabilidade, disseminando e coordenando atividades ligadas à gestão ambiental, no que concerne à geração de renda, recursos naturais, qualidade de vida e meio ambiente. Realizando palestras, oficinas, e cartilha sobre compostagem, biodigestor e a implantação do sistema de coleta seletiva que tiveram a finalidade de contribuir com a melhoria da produção, alimentação e renda da comunidade. 
Neste contexto, é clara a necessidade de mudar o comportamento do assentado em relação à natureza, sob um modelo de desenvolvimento sustentável. Acredita-se que a educação ambiental se constitui em processo pedagógico participativo que poderá permitir aos assentados uma percepção crítica sobre a problemática ambiental.

\section{REVISÃO TEÓRICA}

\section{A educação ambiental e os resíduos sólidos}

Na sociedade moderna, percebe-se uma preocupação com a geração excessiva de produtos e os danos causados ao meio ambiente. Os resíduos sólidos são um problema multidisciplinar que envolve aspectos técnicos, ambientais, financeiros, de marketing, legais e sociais (RIBEIRO et al., 2009).

A Educação Ambiental contribui fortemente para o processo de sensibilização levando à mudança de hábitos e atitudes do homem e sua relação com o ambiente (CRIBB, 2010). Loureiro (2009) argumenta que a Educação Ambiental remete a buscar por democratização da cultura, do acesso e permanência na escola bem como da melhoria do nível cultural da população para compreender melhor a ciência, os avanços científicos e tecnológicos e as possibilidades de solução para diversos problemas de nossa época.

Nesse sentido, a Educação Ambiental requer uma abordagem interdisciplinar, já que lida com a realidade, contemplando todos os aspectos que compõem a questão ambiental e sociocultural e procura estabelecer um diálogo entre as diversas culturas presentes nos mais diversos espaços/tempos sociais, onde a vida cotidiana não é apenas lócus de repetição; é, também, espaço/tempo de produção de conhecimentos válidos e necessários (ALVES, 2004).

Carvalho (2004) afirma que a Educação Ambiental contribui para mudança de valores e atitudes, promovendo a formação de um sujeito ecológico. A Educação Ambiental possui um caráter amplo e complexo, pois envolve diversos campos do saber, voltados para o mesmo objetivo que é promover a sustentabilidade ambiental por meio de novos paradigmas. Para Guimarães (2011), o processo de construção da realidade socioambiental se concretiza através do fazer pedagógico que se almeja para a EA, considerando que o educador ambiental se posiciona como educador e cidadão. Gomes et al. (2015) infere que deve ser trabalhada através da sensibilização ambiental mostrando os déficits das formas de uso dos recursos naturais, das disposições dos resíduos e ocupação existente, visando melhorias para a comunidade local.

Bartholomeu et al. (2011) considera que um dos maiores desafios da geração de resíduos, que acompanha o crescimento demográfico e os níveis de consumo, é a falta de locais para a disposição e tratamento adequado. E consideram que uma das maneiras de diminuir o impacto dos produtos pósconsumo é a triagem na fonte geradora que reduz a contaminação do material reciclável, aumentando a quantidade reaproveitável e comercializável do mesmo, assim como o seu valor de venda junto às empresas recicladoras, gerando benefícios sociais indiretos.

A Política Nacional de Resíduos Sólidos (PNRS), instituída pela Lei no12.305, de 2 de agosto de 2010, dispõe sobre princípios, objetivos e instrumentos, bem como sobre as diretrizes relativas à gestão integrada e ao gerenciamento de resíduos sólidos, incluídos os perigosos, às responsabilidades dos geradores e do 
poder público e aos instrumentos econômicos aplicáveis. Por se tratar de resíduos sólidos, o primeiro passo é a sua definição:

Os resíduos sólidos são material, substância, objeto ou bem descartado resultante de atividades humanas em sociedade, a cuja destinação final se procede, se propõe proceder ou se está obrigado a proceder, nos estados sólidos ou semissólidos, bem como gases contidos em recipientes e líquidos cujas particularidades tornem inviável o seu lançamento na rede pública de esgotos ou em corpos d'água, ou exijam para isso soluções técnica ou economicamente inviável em face da melhor tecnologia disponível. (BRASIL, 2010)

A Política Nacional de Resíduos Sólidos apresenta o conceito de responsabilidade compartilhada referente a logística reversa, na qual as atribuições partem dos produtores, distribuidores e comerciantes, como também dos consumidores e gestores dos serviços de limpeza, a responsabilidade compartilhada se dá a fim de minimizar a quantidade de resíduos sólidos e rejeitos gerados, reduzindo os impactos ambientais e aumentando a qualidade de vida.

Solucionar ou minimizar os problemas resultantes da geração dos resíduos sólidos vem sendo uma das principais questões ambientais. Segundo Siqueira (2001), são propostos cinco princípios básicos: Minimização da geração de resíduos; Maximização da reutilização e reciclagem ambiental adequada; Seleção de processos industriais de produção de materiais menos agressivos ao meio ambiente; Adoção de formas de destinação final ambientalmente adequada; e Expansão dos serviços de coleta relacionados aos resíduos sólidos para toda a população.

Mazzer et al. (2004) argumenta que a legislação vigente coloca como o grande responsável pelos resíduos o gerador, no qual, algumas vezes, não dá o devido tratamento ou destinação aos resíduos, às vezes por falta de informação ou por não estar devidamente amparado por um prestador de serviço responsável, seja ele público ou privado. Diferente das áreas urbanas, as rurais são ainda mais desassistidas, em virtude de não existir coleta domiciliar regular de resíduos sólidos, além de pouca informação sobre o meio ambiental e a preservação dos recursos naturais. Contudo, acabam queimando os resíduos que produzem próximos as suas residências e/ou lançando em terrenos baldios sem nenhuma prática de manejo, acarretando em prejuízo para a saúde de si próprio e do meio ambiente (ALCANTARA, 2010).

\section{A sustentabilidade ambiental em assentamentos rurais}

De acordo com a Instrução Normativa do INCRA №15, de 30 de Março de 2004, o termo 'assentamento', consiste de um conjunto de ações, em área destinada à reforma agrária, planejadas, de natureza interdisciplinar e multissetorial, integradas ao desenvolvimento territorial e regional, definidas com base em diagnósticos precisos acerca do público beneficiário e das áreas a serem trabalhadas, orientadas para utilização racional dos espaços físicos e dos recursos naturais existentes, objetivando a implementação dos sistemas de vivência e produção sustentáveis, na perspectiva do cumprimento da função social da terra e da promoção econômica, social e cultural do(a) trabalhador(a) rural e de seus familiares.

A conquista do assentamento rural faz parte de um processo de disputa territorial que garante a reprodução do modo de vida camponês, permitindo o acesso à terra a trabalhadores, que anseia não se sujeitar ao modo capitalista de produção. Por isso, o assentamento não é simplesmente a concessão de um 
pedaço de terra aos camponeses com pouca ou sem-terra, e sim um território onde se desenvolvem relações de vida e produção diferentes das do capital (FERNANDES, 1996).

O Brasil, assim como outros países em desenvolvimento, enfrenta complexas desigualdades, tanto de ordem econômica, ambiental, social, política e cultural, como também as relativas à cobertura, acesso e qualidade dos serviços de saúde, ainda são acentuadas em razão dos condicionantes históricos de colonização e dominação política e social. Dessa maneira, torna-se ainda mais difícil enfrentar e resolver estes problemas com perspectivas a alcançar a saúde para todos (GAIA, 2005).

Para tanto, Guerra (2012) argumenta que para se alcançar sustentabilidade num projeto de assentamento, por exemplo, isto depende da aptidão agrícola das terras, da organização política dos assentados e da interação entre entidades governamentais, não governamentais e os próprios assentados. Em relação à saúde pública nos assentamentos, a dificuldade de acesso aos serviços assistenciais de saúde foi um dos aspectos mais recorrente no decorrer da análise do banco de dados, de acordo com estudos de Santos (2011). Por outro lado, o acesso aos serviços e programas de saúde eventualmente apresentase com mais dificuldade para a população que vive no campo, sendo sua organização voltada para atender a população urbana.

Santos (2011) aponta que o MST reivindica a atuação de agentes de saúde nas comunidades, bem como implantação do Programa Saúde da Família e a formação de programas que auxiliem em atendimentos preventivos e curativos nas áreas ocupadas. Para Salgado (2012), o forte vínculo que os trabalhadores possuem com o fato da conquista territorial faz com que eles acreditem na Estratégia de Saúde da Família, por confiarem que o próprio espaço em que vivem pode trazer soluções para intervir nos processos relativos à saúde.

Essas condições de trabalho estão completamente vinculadas à possibilidade de criação de animais e ao cultivo de alimentos, sejam estes destinados ao consumo familiar ou para a produçãogeradora de renda. A capacidade de produção de alimentos proporciona aos trabalhadores uma segurança alimentar ascendente, se comparada ao período anterior ao assentamento, como nos acampamentos e, inclusive, antes da inserção na luta pela terra (SANTOS, 2011).

Porém, como aponta Fontoura Junior et al. (2011), ocorre uma naturalização dos riscos em relação ao trabalho no assentamento; riscos como a exposição intensa às intempéries do tempo, picadas de animais e uso de agentes químicos, entre outros, não possuem o tratamento necessário para o cuidado com a saúde. De acordo com relatos de trabalhadores, na maioria das vezes não são tomados cuidados, principalmente no uso de agrotóxicos, embora alguns afirmem que possuem noção acerca desses cuidados.

Conforme pesquisa de Salgado (2012), a vulnerabilidade presente nos assentamentos pode estar associada a fatores sociais e culturais. Assim, o baixo nível de escolaridade da população, que compromete o entendimento de informações técnicas, bem como o acesso insuficiente a serviços e infraestrutura de saneamento, resulta em uma população despreparada para o manejo destas substâncias.

Esta situação possui maior dimensão pelo fato de a agricultura familiar nestes locais ocasionar riscos 
impostos a toda família, incluindo mulheres e crianças. A ausência de um sistema público de saneamento básico, em concomitância com a precariedade dos serviços de saúde, também potencializa o problema, visto que é um fator de extrema importância que atua contra a saúde humana. Além disso, ocorre um acesso indiscriminado à comercialização de agrotóxicos, indicando que há uma fragilidade existente nas políticas de fiscalização e de acompanhamento técnico referente a estes produtos (SALGADO, 2012).

Ações educativas poderiam ser inseridas neste contexto, pois há uma necessidade de resgatar o diálogo com o homem do campo no sentido de se produzir conhecimento relativo ao trabalho e à saúde do trabalhador rural, uma vez que não é possível observar uma aproximação entre técnicos e trabalhadores nos assentamentos. Este distanciamento encontra-se presente na fala de trabalhadores, que relatam ter recebido as terras do governo, mas reivindicam incentivos em muitas áreas, onde está presente o saneamento básico, financiamentos para a compra de material necessário para a produção, e principalmente, apoio em relação à saúde (FONTOURA JÚNIOR et al., 2011).

Dentre algumas alternativas de tratamento dos resíduos se propõe o método de compostagem, a reciclagem, a incineração, o biodigestor, dentre outros. Assim, destaca-se o reaproveitamento como a reintrodução no processo produtivo, de produtos não mais apropriados para o consumo, visando a sua recuperação, e recolocação no mercado, evitando assim, o seu encaminhamento para a disposição final. Já a reciclagem constitui a reintrodução de um resíduo, produto usado, para que possa ser reelaborado gerando um novo produto (MAZZER et al., 2004).

No entanto, existem algumas dificuldades geradas pela falta de critérios de funcionamento, relacionadas a determinadas técnicas que podem ser observados em vários municípios, um exemplo deste mau funcionamento é a degradação causada por queima de resíduos (ALVES, 2003). A logística reversa de embalagens vazias de agrotóxicos consiste basicamente no processo inverso, ou seja, após o agricultor utilizar os agrotóxicos os mesmos têm o compromisso de devolvê-las nos postos de recebimento que por sua vez armazenam essas embalagens e em seguida são retiradas através do modal rodoviário até as centrais de recebimento e encaminhado às empresas responsáveis pela destinação correta, seja para reciclagem ou incineração, pois os mesmos tornar-se-ão novos produtos se integrando ao começo da cadeia (MENDES et al., 2012).

INPEV (2010) orienta o agricultor a realizar a tríplice lavagem das embalagens, garantir seu correto armazenamento temporário e, no prazo de até um ano após a compra, entregar o material na unidade de recebimento indicada na nota fiscal de venda, onde recebe em contrapartida um comprovante que deverá ser mantido ainda por mais um ano para fins de fiscalização, e para reduzir os impactos dessas embalagens no campo.

\section{METODOLOGIA}

\section{Caracterização da pesquisa}

A metodologia adotada para desenvolver esta proposta foi de natureza aplicada, descritiva, com procedimentos de pesquisa-ação, envolvendo avaliações antes e após as intervenções educativas que serão 
desenvolvidas de acordo com o interesse e a realidade dos assentados. Esta proposta iniciou-se em março de 2016 e teve sua conclusão em outubro de 2016, com a percepção ambiental da comunidade do Assentamento Santo Antônio, zona rural do município de Cajazeiras/PB, referente ao manejo dos seus resíduos sólidos e líquidos gerados, e posteriormente, se fez intervenção com ações educativas, promovendo o despertar para o senso de responsabilidade com o meio ambiente, e levando-os a repensar as suas práticas diárias e as consequências delas para a preservação ambiental e para a sustentabilidade local.

Em conformidade com os aspectos éticos e por conhecer o que preconiza a Resolução CNS no466/2012 sobre as normas regulamentadas para pesquisas envolvendo seres humanos e a complexidade que envolve a temática abordada neste projeto, esta pesquisa foi submetida ao Comitê de Ética em Pesquisa da Universidade Federal de Campina Grande.

Para tanto, assumiu-se o compromisso de respeito aos sujeitos abordados, garantindo-lhes medidas de proteção como: sigilo, anonimato e, ainda, o esclarecimento acerca do que será feito com os resultados obtidos neste estudo, por meio do Termo de Consentimento Livre e Esclarecido (TCLE). As técnicas utilizadas para a identificação dos impactos ambientais no referido assentamento foram: a observação participante e questionários. Tais técnicas serão aplicadas com as 32 famílias pertencentes ao Assentamento Rural Santo Antônio, Cajazeiras/PB, e a partir das respostas obtidas realizou-se uma análise em torno da percepção dos referidos moradores do Assentamento em estudo, bem como as mudanças comportamentais depois da educação ambiental.

\section{Descrição da área de estudo}

O município de Cajazeiras pertence à mesorregião do Sertão Paraibano e à microrregião de Cajazeiras, ocupa uma área de $565,899 \mathrm{~km}^{2}$. O acesso a partir de João Pessoa é feito através da BR-230 até Cajazeiras, a qual dista cerca de $465 \mathrm{~km}$ da capital João Pessoa/PB. De acordo com dados do censo do Instituto Brasileiro de Geografia e Estatística (IBGE), realizado no ano de 2010, o referido município tem uma população de 58.446 habitantes e uma população estimada para o ano de 2015 de 61.431 habitantes. A sede municipal apresenta uma altitude de $295 \mathrm{~m}$ e coordenadas geográficas de $38^{\circ} 33^{\prime} 43^{\prime \prime}$ de longitude Oeste e $06^{\circ} 53^{\prime} 24^{\prime \prime}$ de latitude Sul.

O Assentamento Rural Santo Antônio está localizado dentro dos limites do município de Cajazeiras/PB, a uma distância de $15 \mathrm{~km}$ da sede municipal, com coordenadas geográficas de $06^{\circ} 53^{\prime} 13^{\prime \prime}$ latitude Sul e 38023'41" de longitude Oeste e integra o extremo Oeste do Estado da Paraíba, sentido Cajazeiras - Sousa, através da BR-230, conforme ilustrado na figura 1.

O Assentamento abriga uma população de 186 assentados, dispondo de 32 famílias distribuídas em duas vilas na fazenda Santo Antônio (FREITAS et al., 2012). Cada família possui 10ha de terra, e diferente dos demais projetos de assentamento rurais, este possui uma trajetória de permanência e não uma ocupação do lugar. Manteve-se a história dos moradores que acompanharam desde o surgimento da fazenda Santo Antônio até a transformação ou apenas à mudança de nome para assentamento Santo Antônio. Nessa oportunidade, por motivo de dívidas com o banco, o poder público representado, nesse caso, pelo Instituto 
Nacional de Colonização e Reforma Agrária, em 1996, efetivou e legalizou a desapropriação, possibilitando, assim, as famílias que ali habitavam tomarem consciência da condição de donos daquela terra, da qual antes eram moradores.

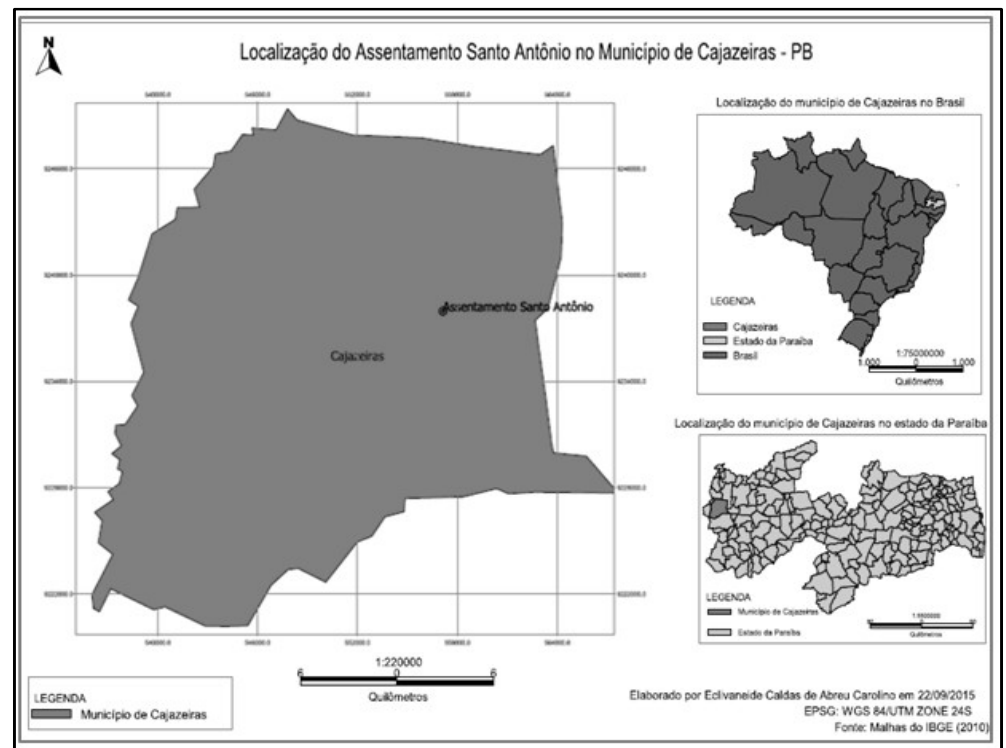

Figura 1: Localização do Assentamento Santo Antônio, Cajazeiras - PB.

O Assentamento Rural Santo Antônio possui uma área total de 669,75ha, com áreas inclusas de: recursos hídricos, estradas carroçáveis, agrovilas, área comunitária, área de serrote e área remanescente incluindo três áreas de reservas florestais. Este possui uma área com potencial em plantas medicinais, potencial hídrico, um assentamento integrante da rede de saúde e alimentação (ARAÚJO, 2005), uma realidade específica, um recorte de uma paisagem semiárida, de clima quente e seco, que se caracteriza como o mais representativo da microrregião de Cajazeiras/PB, considerando sua marca histórica e as referências dos seus moradores que conservam até a atualidade, os aspectos originais dos antigos donos das terras, expressando a memória do lugar.

A vegetação constituída pela 'Caatinga' hiperxerófila/hipoxerófila, encontra-se degradada pela ação antrópica, seja pela retirada da madeira para diversos fins, queima, e uso como pasto. Apesar dessas ações, a região apresenta um potencial considerável de espécies medicinais e alimentar, matéria-prima para remédios, de grande utilidade para a comunidade.

\section{Observação Participante}

Segundo Lakatos et al. (2007), esta técnica de coleta de dados requer a participação real do pesquisador com a comunidade ou grupo, visando adquirir a confiança do grupo em estudo, e fazê-los compreenderem a importância da investigação. Neste contexto, as visitas técnicas foram realizadas no local em estudo, promovendo a observação do pesquisador na área de estudo, registrando informações e situações quanto aos problemas socioeconômicos e ambientais existentes no assentamento rural Santo Antônio. E após, as medidas educativas, advindas das palestras, oficinas e das cartilhas que ofereceram subsídios aos habitantes do referido assentamento, sobre as alternativas de tratamento e disposição final 
dos resíduos gerados na localidade, e a compreensão sobre os agravos a saúde trazidos pelo manejo inadequado dos resíduos.

\section{Questionários}

Consiste de um instrumento investigativo que contém uma série ordenada de perguntas, as quais devem ser respondidas por escrito e sem a presença do entrevistador. Este objetiva levantar opiniões, crenças, sentimentos, interesses, expectativas, situações vivenciadas das pessoas do local de estudo (LAKATOS et al., 2007). Os questionários foram aplicados aos representantes das 32 famílias dos assentados, antes e após as ações educativas. Estes foram elaborados com perguntas objetivas, as quais contemplaram temas como o manejo dos resíduos, coleta seletiva, meio ambiente e a educação ambiental no local, a sustentabilidade do assentamento verificando os aspectos social e econômico, entre outros.

\section{Palestras e Cartilhas Educativas}

A partir dos problemas ambientais, sociais e econômicos que foram levantados durante a compilação dos dados por meio de questionários e da observação participante, foram promovidas palestras no próprio local de estudo para os assentados sobre o manejo adequado dos resíduos sólidos e líquidos, mostrando as possibilidades de alternativas de conversão e/ou reaproveitamento desses em outros produtos tais como: compostagem, horta ecológica, bioenergia, entre outras que poderão ser adotadas como fator sustentável para o próprio assentamento.

Na elaboração das cartilhas, utilizou-se como fontes de pesquisas: livros, sites especializados nos temas abordados, artigos científicos disponíveis gratuitamente nos principais indexadores online (Scielo, Periódico Capes e Google Acadêmico), realizando revisões bibliográficas durante março a outubro de 2016. A linguagem adotada na redação da cartilha foi acessível e de fácil compreensão, a ser difundida entre pessoas de diversas faixas etárias, gênero e níveis de escolaridade no referido assentamento rural.

Esta se destina ao compartilhamento de conhecimentos sobre educação ambiental abordando temas como sustentabilidade, compostagem, biodigestor e reaproveitamento alcançar especialmente a população residente no Assentamento Rural Santo Antônio em Cajazeiras/PB, composta pelos seguintes tópicos: Apresentação; Educação ambiental e sustentabilidade em assentamentos rurais; Coleta seletiva; O que é reaproveitamento?; O que é reciclagem? Biodigestor; Compostagem; Artesanato; Como criar artesanatos?; e Referências; cada item contendo informações relevantes e de fácil assimilação. Trata-se de um material didático que ajudará junto às demais práticas educativas aplicadas no assentamento, na sensibilização dos assentados para que adotem atitudes ambientalmente corretas na relação com meio ambiente.

\section{RESULTADOS E DISCUSSÃO}

\section{Panoramas do assentamento rural pesquisado sem a intervenção participativa}

A pesquisa foi iniciada pela observação fiel do local, sem nenhuma intervenção educativa, buscando averiguar o quadro de sensibilização dos habitantes do assentamento rural Santo Antônio-PB com o seu meio 
ambiente, conforme retratado na figura 2. Constatou-se que, a maioria dos habitantes do assentamento rural Santo Antônio - PB é do sexo feminino, exatamente 62,5 \% dos entrevistados foram de mulheres, contra 37,5\% de pessoas do sexo masculino. As faixas etárias desses moradores compreendem entre grupos de: 6170 anos (30\%), 31-40 anos (15,63\%) e a faixa de $41-50$ (12,5\%), e, portanto, predominante de assentados na faixa da terceira idade.

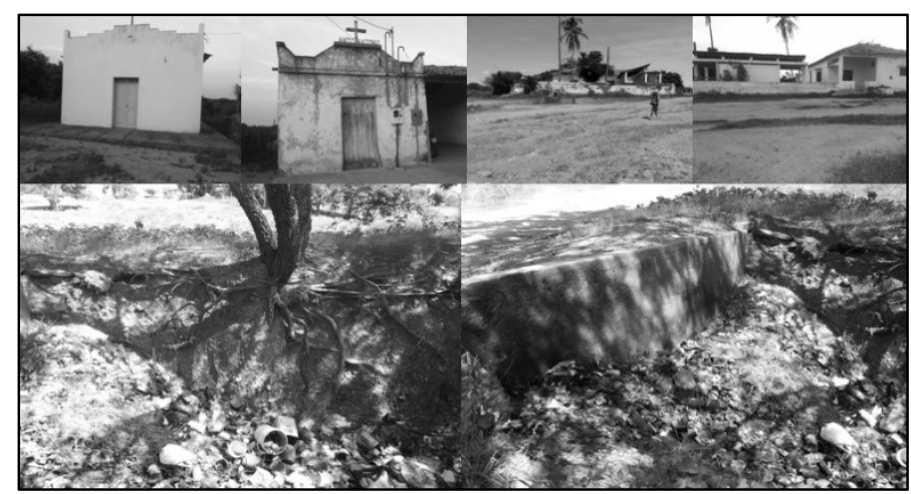

Figura 2: Visão geral do Assentamento Rural Santo Antônio/PB antes das intervenções educativas.

Verificou-se através de outros estudos, a exemplo do assentamento São João II localizado no limite entre os municípios de Palmas/TO e Porto Nacional/TO, que do total dos entrevistados, os homens constituem 56,7\% dos assentados (MARTINS et al., 2010). Assim como para a população do assentamento Veneza, localizado no município paraibano de Aparecida, quanto à questão de gênero, é representada atualmente com um percentual de 51\% do sexo masculino e $49 \%$ do sexo feminino (QUEIROGA et al., 2014).

Considerou-se as projeções do IBGE (2016), a proporção de pessoas do sexo feminino no Brasil em 2016 é de aproximadamente 50,64\%, logo, quando se compara com o perfil do assentamento, percebe-se que este apresenta uma proporção maior de pessoas do sexo feminino, portanto, acima dos dados nacionais. Nos assentamentos pesquisados por Rosa et al. (2011) no município de Tamarana/PR, 49\% são mulheres e $51 \%$ são homens.

Observou-se que a proporção de assentados acima de 60 anos é muito acima da média nacional. Para o IBGE (2016), pouco mais de $12 \%$ da população brasileira se encontra nessa faixa etária. Um estudo no assentamento Lagoa Grande no município mato-grossense de Dourados, Sangalli (2013) constatou que a proporção de pessoas acima de 60 anos era de 16,3\%, mais próxima da média nacional e os grupos com maior número de pessoas foram os das faixas etárias de $11-20$ anos e $41-50$ anos (18,5\% cada). No assentamento paulista Estrela da Ilha, Simonato et al. (2014) verificou que a maioria dos entrevistados está entre $40-50$ anos (37\%).

No Assentamento Rural Santo Antônio/PB percebeu-se que aparece com uma quantificação relevante a quantidade de entrevistados cuja origem é rural, em termos exatos, estes representaram $84,4 \%$ contra $15,6 \%$ de origem urbana. E, portanto, possuem níveis distintos de escolaridade, conforme exposto no Gráfico 1. Sendo constituídos de alfabetizados com percentual de 31,25\% até o ensino superior incompleto, passando por categorias intermediárias como ensino fundamental incompleto 15,62\%, por exemplo. 


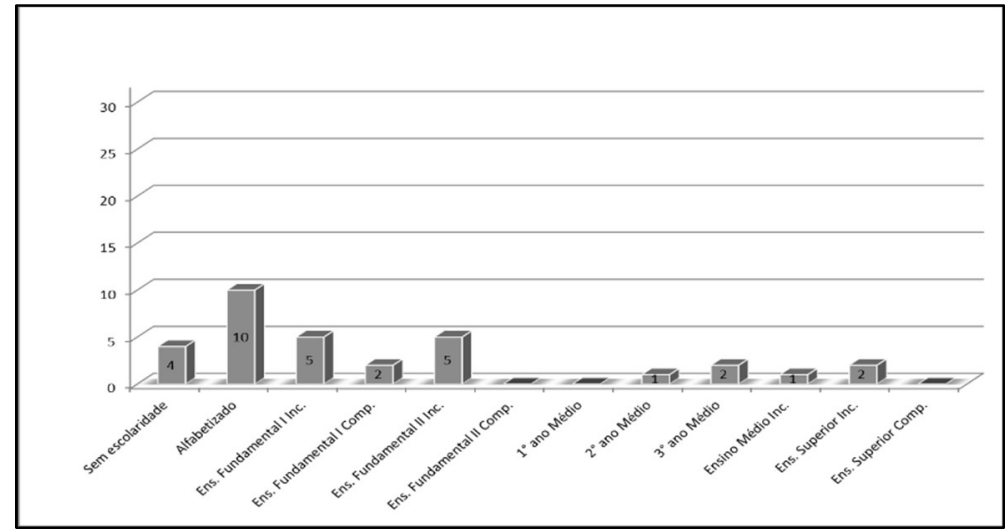

Gráfico 1: Nível de escolaridade dos assentados do Assentamento Santo Antônio, Cajazeiras/PB, 2016.

A maior parte dos entrevistados faz parte de família formada de 2 a 5 pessoas; em termos percentuais, $68,75 \%$. Apenas $12,5 \%$ dos entrevistados pertencem a famílias com mais de cinco pessoas. Esse fato pode estar relacionado com a redução da taxa de fecundidade, famílias numerosas são cada vez mais incomuns na conjuntura atual. Quanto ao tempo de moradia dos assentados, proposto no gráfico 2, foram observados em seus relatos intervalos entre 10 a 20 anos e mais de 50 , em termos percentuais $31,3 \%$ e $28,1 \%$ dos entrevistados, respectivamente, 12,5\% moram no assentamento entre 5 a 10 anos, e 12,5\% entre 20 e 30 anos.

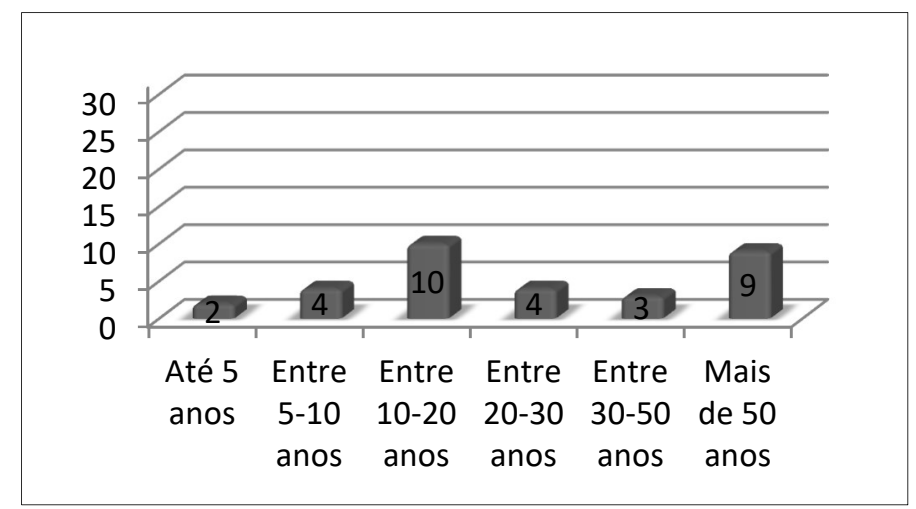

Gráfico 2: Tempo de moradia dos assentados do Assentamento Santo Antônio, Cajazeiras/PB, 2016.

Entre os agricultores escolhidos para a entrevista por Lacerda et al. (2010), na Comunidade São Francisco no município de Conceição/PB, 83\% deles são provenientes da zona rural, ou seja, esses agricultores nasceram na comunidade e vivem no mesmo local até hoje. Verifica-se que $17 \%$ dos entrevistados no seu estudo são provenientes da zona urbana, onde se observa um caminho contrário do ocorrido normalmente, ou seja, o inverso do êxodo rural. Constatou-se ainda que mais de $70 \%$ das famílias era formada por quatro integrantes.

No que concerne aos tipos e condições de moradia, foram observados que os habitantes do assentamento em estudo, possuem residência de alvenaria (90\%), seguido de madeira, e material reciclado. Questionados se porventura recebem algum tipo de auxílio do Governo Federal, a pesquisa apresentou índices de $56,25 \%$ de assentados que não recebe auxílio do governo Federal e apenas $43,75 \%$ recebem o auxílio de Programas Federais, sendo, portanto, 78\% do Programa Bolsa Família, 22\% recebem auxílio de outros programas. 
Para Queiroga et al. (2014), em relação ao acesso das famílias do Assentamento Paraibano Veneza aos benefícios sociais, foi identificada a existência de um número significante de famílias que recebem apoio do Governo Federal, em termos percentuais, $72,74 \%$ das famílias são beneficiadas com programas Federais. E de acordo com Simonato et al. (2014) em seu estudo infere que esses domicílios, em alvenaria, se caracterizam por serem gerados a partir da autoconstrução, ou seja, é a população construindo com seus próprios recursos, sem interferência do poder público nem mesmo para verificar condições de segurança e bem-estar.

Nas famílias assistidas com programas Federais de assistência, destaca-se o Programa Bolsa Família, correspondendo a 54,55\% dos valores recebidos, em seguida, se constatou a aposentadoria por Trabalhador Rural (9,09\%) e o Benefício da Prestação Continuada (BPC), correspondente a 4,55\%, dados referentes ao Assentamento Veneza, situado no município de Aparecida/PB (QUEIROGA, et al., 2014).

Para Santana et al. (2008), cerca de $20 \%$ das famílias de agricultores na Comunidade Pindoba (Areia/PB) recebem do Governo Federal o benefício do bolsa família que compreende (Fome Zero, BolsaEscola e Auxílio-Gás). Verifica-se também que 35\% são beneficiados apenas pelo Auxílio-Gás e Fome Zero por não possuírem filhos na escola. Também foi observado que $45 \%$ dos entrevistados são agraciados com a aposentadoria, inferindo-se assim que, boa parte da população da comunidade é composta por pessoas idosas.

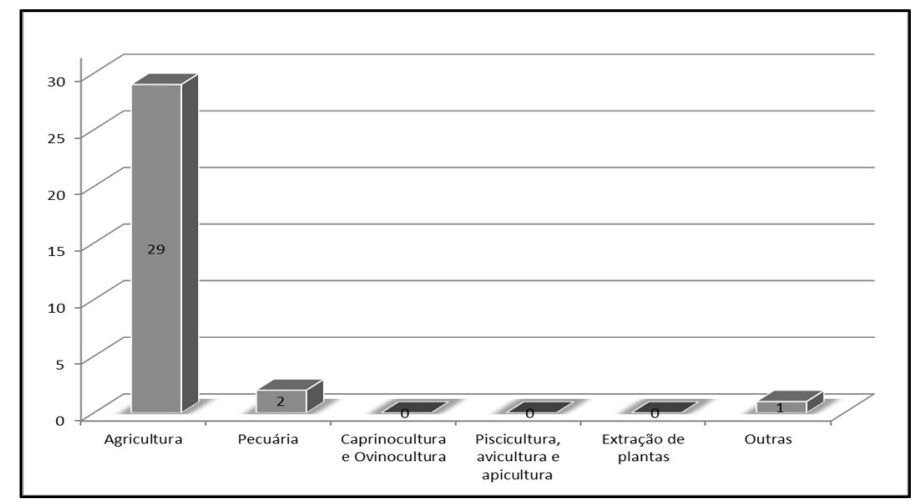

Gráfico 3: Atividades desenvolvidas no Assentamento Santo Antônio, Cajazeiras/PB, 2016.

No assentamento Lagoa Grande em Dourados no Mato Grosso do Sul, segundo Sangalli (2013), 52,9\% dos assentados conhecem apenas o PRONAF, do qual participaram ou ainda estão vinculados. Os outros programas que os assentados participaram são: PNAE, PAA Leite e bolsa estiagem. No gráfico 3 estão elencadas as atividades desenvolvidas no Assentamento Rural Santo Antônio, Cajazeiras/PB. Ampla maioria das famílias tem como principal atividade a agricultura, seguida da pecuária. Mais de $90 \%$ praticam a agricultura e pouco mais de $6 \%$ praticam a pecuária, sendo que as formas mais comuns de preparo do solo no assentamento provêm de quase $60 \%$ dos moradores que fazem a capina manual; aproximadamente $22 \%$ dos entrevistados faz uso de tratores; 6,3\% utilizam a tração animal; e 12,5\% não utilizam nenhuma das formas citadas anteriormente.

Ramalho (2014), observando as comunidades rurais no município baiano do Uma, argumentou quanto ao preparo do solo que a técnica manual é utilizada por $96 \%$ dos agricultores entrevistados, a tração 
mecânica foi apontada apenas por $2 \%$ deles, e não houve nenhum pronunciamento dos agricultores em relação à técnica com tração animal.

Quanto às profissões dos moradores do assentamento Santo Antônio, 72\% são agricultores, seguida de $15,6 \%$ doméstica e 3,1\% pedreiro. E neste instante, foi perguntado sobre o êxodo rural de maneira simples, por meio do seguinte questionamento: 'Algum membro da família mudou-se para a cidade?', e então, foi revelado que $41 \%$ dos entrevistados responderam 'Sim' e 59\% responderam negativamente.

Num diagnóstico ambiental e produtivo de comunidades localizadas no Sul da Bahia, Ramalho (2014) constatou que a grande maioria dos filhos dos produtores prefere ao terminar os estudos trabalhar e morar na cidade. Alguns afirmaram que apesar da infância e adolescência ter sido totalmente no meio rural, as influências da cidade conduziram os mesmos a 'não ter identidade com a vida no campo'.

Sobre a presença de animais nas suas propriedades, $71,8 \%$ possuem presença de animais nas suas propriedades e $28,1 \%$ responderam negativamente. Percebeu-se, que a maioria dos assentados possui renda total no intervalo de 1 a 3 salários mínimos; 87,5\% dos moradores têm essa renda; 6,3\% ganham menos de um salário mínimo; 3,1\% disseram não apresentar renda; e outros 3,1\% não souberam informar.

Houve a indagação a respeito da participação dos moradores em cursos de capacitação promovidos pelas instituições ou organizações, e cerca de $52,35 \%$ dos assentados participaram de curso promovido pelo INCRA (Instituto Nacional de Colonização e Reforma Agrária); 13,52\% pela EMATER; 5,40 \% promovido pelo MST (Movimento dos Sem Terra); e 24,32\% disseram que não participaram de cursos promovidos por essas organizações ou instituições.

Os entrevistados deram sua opinião em relação às condições das vias que dão acesso ao assentamento Santo Antônio/PB, arguindo que as vias de acesso estão em boas condições, $(65,6 \%$ dos assentados), 31\% em estado regular e 3,13\% em condições péssimas. Questionados quanto à assistência de saúde oferecida pelo governo municipal, $40,6 \%$ classificaram como boa, 37,5\% regular, e $21,9 \%$ enfatizaram que a assistência era péssima. Enquanto, para as formas de comunicação mais usuais dos assentados ficaram evidente que $94 \%$ faz uso por meio de celulares, seguidos da telefonia fixa e a rádio comunitária, com percentuais muito menores ao da telefonia móvel, com 3,1\% cada.

No que concerne à utilização de qualquer tipo de fontes energéticas no assentamento, estes fazem uso apenas de energia elétrica, não citando outro modo de energia alternativa sustentável, a exemplo do biogás proveniente de biodigestor. Por outro lado, quanto ao aproveitamento de algum tipo de material que iria para o lixo, o plástico tem sido um dos mais reutilizados por $75 \%$ dos assentados, seguido de pouco mais de $8 \%$ dos moradores que reaproveitam papel, vidro e metal, conforme o gráfico 4 .

Entre os assentados que realizam reaproveitamento, aproximadamente $50 \%$ dos assentados faz o uso novamente de materiais advindos do 'lixo', ou seja, fazem a reutilização para algum fim e $10 \%$ realizam algum tipo de transformação (Gráfico 5). Em relação ao destino do lixo domiciliar no assentamento, 100\% dos entrevistados afirmou fazer o aterramento misturando resíduo sólido e orgânico, a queimada ou dispor o lixo produzido a céu aberto. 


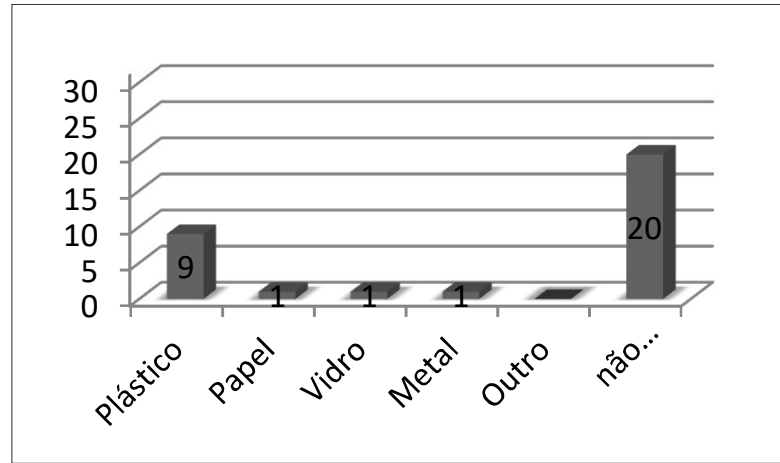

Gráfico 4: Tipos de materiais reaproveitados no Assentamento Santo Antônio, Cajazeiras/PB, 2016.

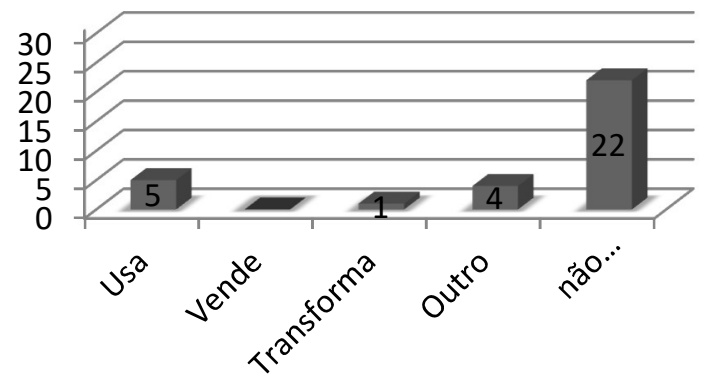

Gráfico 5: Destino dado aos materiais descartados como 'lixo' no Assentamento Santo Antônio, Cajazeiras/PB, 2016.

Ao confrontar esses resultados com outros estudos, percebeu-se que os resíduos sólidos produzidos nas propriedades do Assentamento Congonhas Aberlado Luz/SC, na sua maioria (47,17\%), são queimados, enterrados $(37,73 \%)$ e, somente $15,10 \%$ utiliza estes resíduos, quando de origem orgânica, para a compostagem, podendo reutilizá-lo no ciclo de nutrientes (PAIM et al., 2009).

Ramalho (2014) argumenta que o lixo é um problema identificado nas comunidades, e as queimadas são utilizadas por $71 \%$ dos agricultores, e uma porcentagem menor (16\%) usam buracos para colocar o lixo inorgânico e somente $9 \%$ assumiram que deixam o lixo a céu aberto. Os resíduos dispostos nas proximidades das residências contribuem para o aumento dos índices de proliferação de pragas e insetos, vetores de graves doenças que afetam os moradores locais.

Para Sousa (2015), as condições de destinação de resíduos sólidos domiciliares no assentamento são bastante precárias no assentamento, sendo que $54 \%$ dos moradores queimam seus resíduos, $16 \%$ queimam uma parcela e enterram outra, $12 \%$ dispõem a céu aberto e apenas $8 \%$ levam ao contêiner do sistema público de coleta da Prefeitura Municipal de Palmas.

Com base feita em um estudo no assentamento Jacu em Pombal/PB, Araújo (2014) relata que a presença de lixo naquela localidade é um aspecto negativo na manutenção dos cuidados ambientais, a autora constatou três maneiras distintas de destinação do lixo por parte dos moradores do referido local: queima, enterramento e disposição a céu aberto.

Perguntado aos assentados Santo Antônio/PB, sobre o que fez despertar o interesse em reaproveitar materiais, tem-se que: $41,67 \%$ dos moradores disseram que o interesse surgiu após campanhas de conscientização, 33,33\% veio oriundo de necessidades econômicas e pouco mais de $8 \%$ apontaram o jornal como meio despertador desse interesse (Gráfico 6).

Os assentados opinaram a respeito dos prováveis impactos causados pela disposição inadequada de resíduos sólidos. Computou-se que a metade dos habitantes relatou a disposição inapropriada dos resíduos provoca doenças, 31,25\% que esse tipo de disposição causa poluição dos elementos naturais, 15,63\% que a incorreta disposição do lixo traz prejuízos para a agricultura e apenas 3\% considera que essa prática não provoca males. 


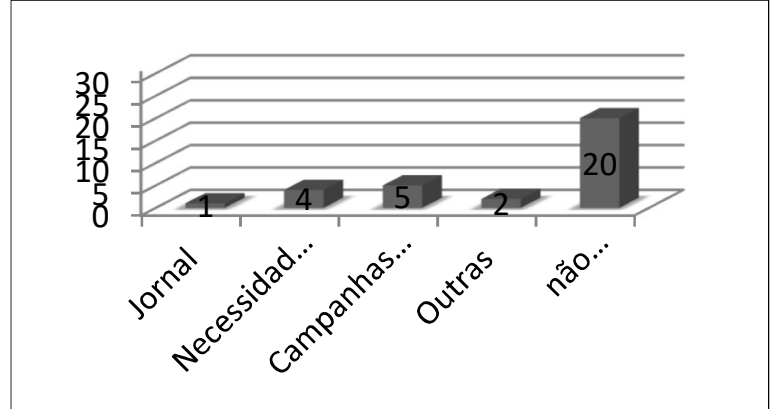

Gráfico 6: Formas de sensibilização sobre reaproveitamento de materiais recicláveis, Assentamento Santo Antônio, Cajazeiras/PB, 2016.
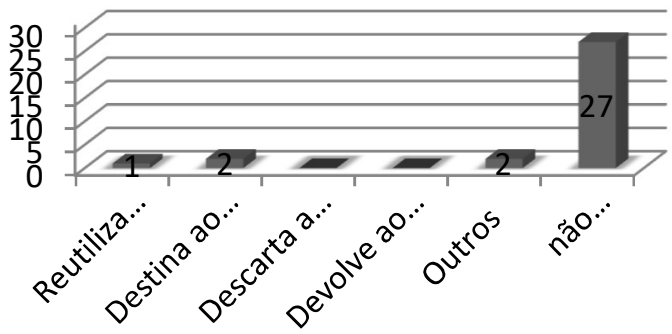

Gráfico 7: Destino dado às embalagens vazias de agrotóxicos, Assentamento Santo Antônio, Cajazeiras/PB, 2016.

Tratou-se a respeito das formas de acondicionamento dos resíduos pelos moradores do assentamento Santo Antônio/PB, visto que $68,75 \%$ dos entrevistados acondicionam os resíduos em sacos plásticos, pouco mais de $28 \%$ utilizam baldes plásticos para a guarda dos resíduos, $3 \%$ utilizam outros materiais ou recipientes, nenhum respondeu que utilizava vasilhame de pneu ou outro material. Em relação a se utilizavam ou não nas suas produções agrícolas fertilizantes, adubos químicos, pesticidas e/ou inseticidas. Evidenciou-se que a maioria ampla não faz uso desses produtos, o que corresponde a $84,4 \%$ e apenas $15,6 \%$ responderam afirmativamente ao questionamento.

Para os moradores que utilizavam fertilizantes, adubos químicos e afins foram indagados a respeito do destino que estes davam as embalagens vazias dos agrotóxicos. Considerando as respostas expressas no Gráfico 7, percebe-se que $40 \%$ disseram que jogam as embalagens vazias no lixo comum da casa, $20 \%$ reutiliza para outros fins e outros $40 \%$ dão um destino que não foi elencado nas opções da entrevista. Com relação ao destino das fezes animais, $40,63 \%$ dos moradores as utilizam para a compostagem, $28,13 \%$ dispõem esses resíduos em terrenos baldios e de 31,25\% não responderam ao questionamento (Gráfico 8 ).

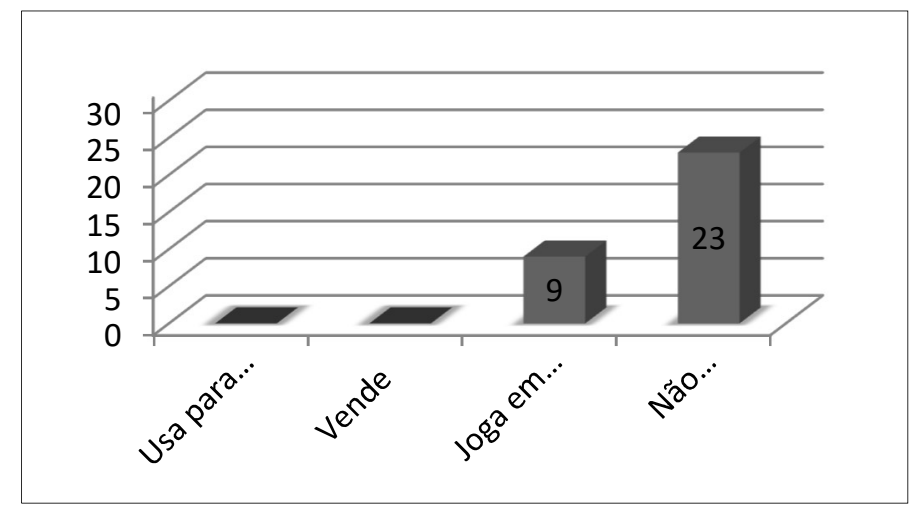

Gráfico 8: Destino dado às fezes dos animais no Assentamento Santo Antônio, Cajazeiras/PB, 2016.

No Assentamento Rural Santo Antônio as formas de captação de água mais recorrentes de acordo com o levantamento entre os assentados, é a cisterna, em termos percentuais corresponde a 53,13\%, seguida de $21,87 \%$ que captam água de rio ou riacho, $18,75 \%$ utilizam poços tubulares e pouco mais de $6 \%$ captam água de açudes ou barreiros. Com relação aos tipos de tratamento dados a água de abastecimento humano os mais comuns foram à cloração e a filtração. Mais de $84 \%$ dos assentados fazem a cloração da água para consumo próprio e 15,6\% realiza a filtração, nenhum morador realiza a fervura da água ou outro tipo de tratamento. 
A percepção dos referidos moradores quando perguntado sobre as prováveis mudanças que teriam acontecido na região, apenas $56,25 \%$ constataram as modificações ocorridas, enquanto que $43,75 \%$ não visualizaram. E, para o destino dado aos seus esgotos residenciais. As três formas identificadas foram: fossa negra (40,63\%); fossa séptica (21,87\%); e esgotos dispostos a céu aberto (37,5\%), tratada no gráfico 9.

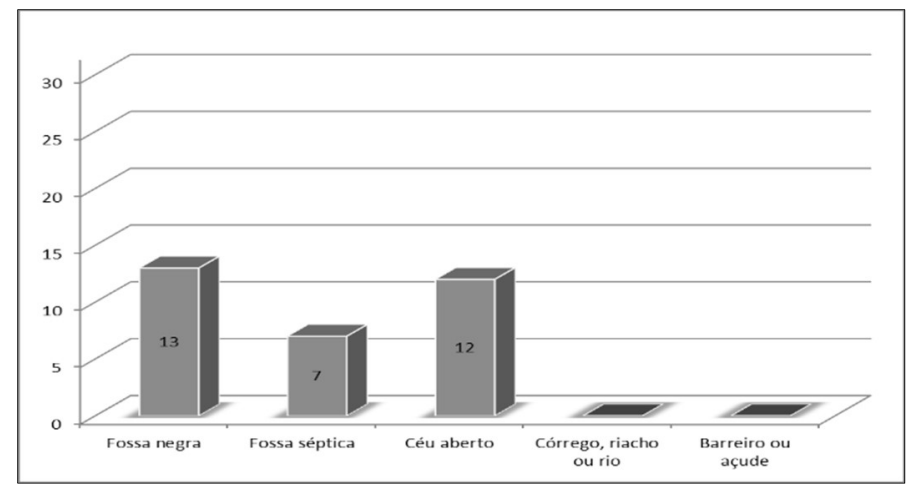

Gráfico 9: Destino dado aos esgotos das residências do Assentamento Santo Antônio, Cajazeiras/PB, 2016.

Sobre a temática 'educação ambiental', $78.13 \%$ tem conhecimento sobre o assunto, contra $21,87 \%$ dos assentados que desconhecem plenamente, como proposto no gráfico 10. A respeito da 'coleta seletiva', os assentados foram indagados se tinham conhecimento ou se sabiam o que era a coleta seletiva, e, portanto, verificou-se que a $62,5 \%$ afirmaram que sim, contra $37,5 \%$ não saber a respeito.

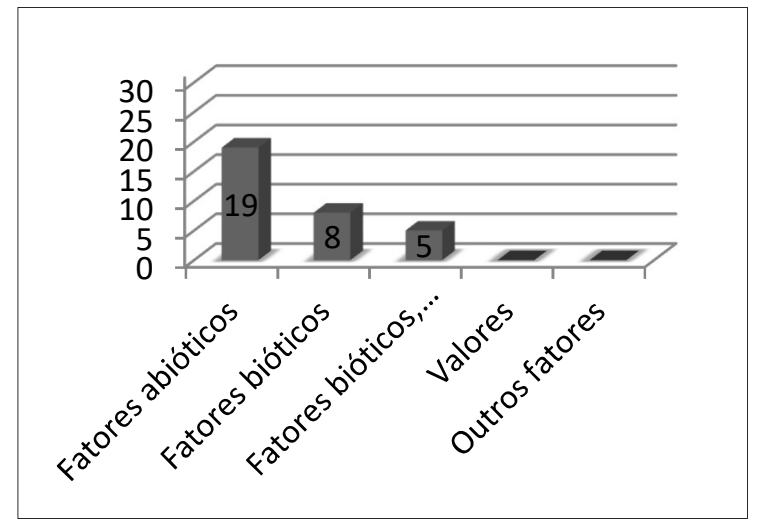

Gráfico 10: A educação ambiental como ferramenta de sustentabilidade, Assentamento Santo Antônio, Cajazeiras/PB, 2016.

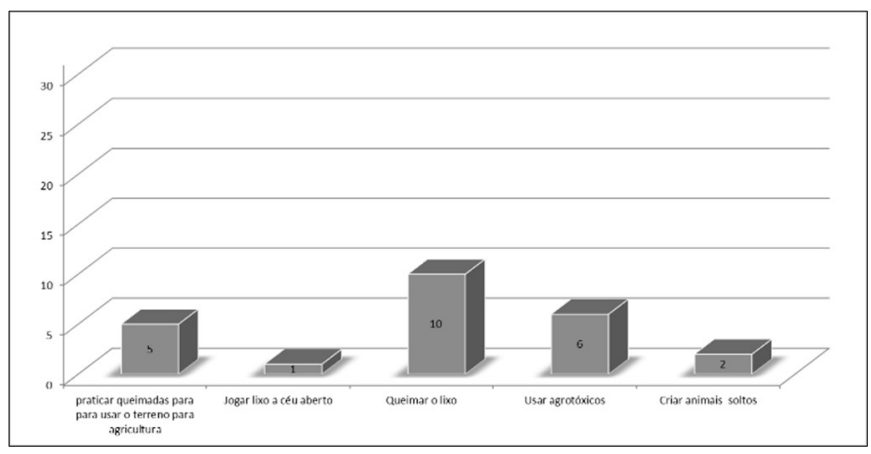

Gráfico 11: Práticas que geram impactos ao meio ambiente na percepção do assentado, Assentamento Santo Antônio, Cajazeiras/PB, 2016.

Arguidos sobre quais seriam os fatores de formação do meio ambiente. 59,37\% afirmou que o ambiente é formado apenas por fatores abióticos, como o ar, o solo e a água, $25 \%$ afirmou que é formado por fatores bióticos como os animais e a vegetação e 15,625\% diz que o meio ambiente é formado pela interação dos fatores abióticos, bióticos e pelos fatores culturais.

A responsabilidade de proteção à natureza foi tema de questionamento feito aos moradores, dos quais $68,75 \%$ afirmaram que a responsabilidade de proteger o ambiente é da sociedade em geral, enquanto, $21,87 \%$ acham que é do governo e pouco mais de $9 \%$ diz que são das ONGs de defesa ambiental essa responsabilidade. Provocados a respeito da possibilidade dos seus trabalhos gerarem danos ao meio ambiente. $3 / 4$ disseram que sim, ou seja, $75 \%$ e $25 \%$ dos entrevistados afirmaram que o seu trabalho não causa danos para a natureza. 
Para aqueles que responderam afirmativamente a indagação proposta na gráfico 11, arguiu-se sobre as práticas que geram impactos ao meio ambiente. $28,33 \%$ apontaram que praticar queimadas com o objetivo de limpar o terreno para uso posterior, causam danos ao meio ambiente; $4,17 \%$ considera que jogar o lixo em terrenos pode causar impactos na natureza; $8,3 \%$ diz que a criação de animais soltos pode acarretar problemas ao meio ambiente; $25 \%$ diz que o uso de agrotóxicos nos cultivos é maléfica e maior porcentagem $(41,67 \%)$ diz que a queima do resíduo sólido pode implicar em danos ao ambiente.

Haubricht et al. (2014) questionou os moradores, do Assentamento Vila Rural I, no município de Alta Floresta/MT, sobre o conceito de meio ambiente, $76 \%$ dos moradores responderam que é a interação das diferentes formas de vida existentes no planeta, incluindo os seres humanos, $16 \%$ acreditam que são os recursos naturais que os seres humanos dependem para viver, já $8 \%$ que são os animais e as plantas que devemos preservar.

Guimarães et al. (2013), em um estudo a respeito da percepção ambiental de produtores rurais do Assentamento Amaralina, em Vitória da Conquista, revelou 75,38\% considerou que todos são responsáveis para resolver os problemas do meio ambiente. Isto indicar que uma parcela significativa dos entrevistados percebe os impactos negativos causados à natureza pelo ser humano, e entendem que, para que os problemas ambientais sejam resolvidos com maior precisão é necessária à colaboração de todos. Quanto à solução dos problemas ambientais, os moradores do assentamento Vila Rural I no município de Alta FlorestaMT, afirmam que os responsáveis por resolver os problemas ambientais somos todos nós (84\%), seguido do governo Federal (12\%) (HAUBRICHT et al., 2014).

\section{CONCLUSÃO}

Ficou demonstrado neste trabalho, que a construção de uma percepção de sustentabilidade está intimamente vinculada ao processo pedagógico, e requer a educação ambiental associada à ideia de uma educação crítica e transformadora do sentir, pensar e agir. A pesquisa contribuiu ainda para promover condições que permitirão ampliar o poder social dos assentados, através de uma consciência crítica.

Foi uma experiência significativa, uma vez que propiciou a proposta de educação em constante diálogo com o meio ambiente, representou um resgate de conhecimentos locais favoráveis ao desenvolvimento de práticas de valorização dos recursos naturais; a valorização dos saberes locais interpretados pelas leituras dos participantes a respeito da participação, vulnerabilidades, superações e convivência, articulados por uma educação ambiental; a expressão nas relações históricas de identidade com o meio ambiente; a modificação da realidade sobre uma forma inovadora de vivenciar a prática do manejo direto de forma orgânica com a natureza; e uma forma consciente de compreender a natureza, seus limites, desafios e impedimentos, com um olhar de quem está inserido no ambiente, experimentando suas mutações e resistências às condições naturais.

Os resultados apresentados no trabalho podem servir como ferramentas norteadoras no delinear de novos projetos que visem o uso sustentável dos recursos naturais. Porém, é importante ressaltar que os objetivos sobre a compreensão da natureza, a partir do conhecimento/saber e o despertar da consciência 
ambiental não foram alcançados em sua plenitude, pois ainda há muito que ser trabalhado. Entretanto, entende-se que com esta pesquisa novos questionamentos irão surgir e abrirão espaços para a continuidade deste projeto. Assim, o trabalho pode ser continuado por outro pesquisador, abrindo novos caminhos.

\section{REFERÊNCIAS}

ABRELPE. Associação Brasileira de Empresas de Limpeza Pública e Resíduos Especiais. Panorama dos Resíduos Sólidos no Brasil. São Paulo: ABRELPE, 2013.

ALCANTARA, P. F.. Concepção de resíduos sólidos em áreas rurais de Nova Friburgo (RJ, Brasil): do consumo ao manejo. Dissertação (Mestrado em Saúde Pública e Meio Ambiente) Escola Nacional de Saúde Pública Sergio Arouca, Rio de Janeiro, 2010

ALVES, N.. Criar currículo no cotidiano. São Paulo: Cortez Editora, 2004.

ALVES, R. O.. Análise da viabilidade econômica da implantação de uma indústria de reciclagem de embalagens e PET na região de Ouro Preto. Monografia (Graduação em Engenharia de Produção) - Universidade Federal de Ouro Preto, Ouro Preto, 2003.

\section{ARAUJO, M. M.. Saúde e alimentação no Alto Sertão} Paraibano. Cajazeiras. 2005.

BARTHOLOMEU, D. B.; BRANCO, J. E. H.; CAIXETA FILHO, J. V.. A Logística de transporte dos resíduos sólidos domiciliares. In: BARTHOLOMEU, D. B.; CAIXETA FILHO, J. V.. Logística ambiental de resíduos sólidos. São Paulo: Atlas, 2011.

BILGEN, S.. Structure and environmental impact of global energy consumption. Renewable and Sustainable Energy Reviews, v.38, p.890-902, 2014. DOI: http://doi.org/10.1016/j.rser.2014.07.004

BRASIL. Lei n.12305 de 02 de agosto de 2010. Institui a Política Nacional de Resíduos Sólidos; altera a Lei 9.605, de 12 de fevereiro de 1998; e dá outras providências. Brasília, DOU, 2010

CRIBB, S. L. S. P.. Contribuições da educação ambiental e horta escolar na promoção de melhorias ao ensino, à saúde e ao ambiente. REMPEC - Ensino, Saúde e Ambiente, v.3, n.1, p.42-60, 2010.

FERNANDES, B. M.. Espacialização e territorialização da luta pela terra: a formação do MST - Movimento dos Trabalhadores Rurais Sem-terra em São Paulo. Dissertação (Mestrado em Geografia Humana) - Universidade de São Paulo, São Paulo, 1996.

FONTOURA JUNIOR, E. E.; SOUZA, K. R.; RENOVATO, R. D.; SALES, C. M.. Relações de saúde e trabalho em assentamento rural do MST na região de fronteira BrasilParaguai. Trabalho, Educação e Saúde, v.9, n.3, p.379-397, 2011.

FREITAS, J. P.; NETO, M. F. S.; FREITAS, F. E.; LINHARES, E. J.; MEDEIROS, M. C. S.. Análise do uso e ocupação do solo no Assentamento Santo Antônio no município de Cajazeiras-PB. Geoambiente On-line, Jataí, n.18, 2012.
GAIA, M. C. M.. Saúde como prática da liberdade: as práticas de famílias em um acampamento do MST e o desenvolvimento de estratégias de educação popular em saúde. Dissertação (Mestrado em Ciências) - Fundação Oswaldo Cruz, Belo Horizonte, 2015.

GOMES, R. K. S.; SILVA, M. C. L.; MEDEIROS, M. M.. A sustentabilidade da educação socioambiental no Assentamento do Anauerapucu, Amazônia Amapaense. REMEA, v.32, n.1, p.1-15, 2015

GUERRA, N.. Resíduos sólidos urbanos: impactos socioambientais e perspectiva de manejo sustentável com inclusão social. Ciência \& Saúde Coletiva. v.17, n.6. p.15031510, 2012. http://doi.org/10.1590/S1413$\underline{81232012000600014}$

GUIMARÃES, M.. A formação de educadores ambientais. Campinas, São Paulo: Papirus, 2011.

GUIMARÃES, S. O.; PAULA, A. Análise da percepção ambiental de produtores rurais do Assentamento Amaralina, Vitória da Conquista/BA. Enciclopédia Biosfera, Goiânia, v.9, n.16; p.1662-1680, 2013.

HAUBRICHT, D. M.; FIORINI, F. M.. Percepção ambiental dos moradores do assentamento vila rural I do município de Alta Floresta/MT. Revista da Universidade Vale do Rio Verde, Três Corações, v.12, n.1, p.248-256, 2014. DOI: http://doi.org/10.5892/ruvrd.v12i1.1366

IBGE. Instituto Brasileiro de Geografia e Estatística. Pesquisa de informações básicas municipais: perfil dos municípios brasileiros. Rio de Janeiro: IBGE, 2010.

IBGE. Instituto Brasileiro de Geografia e Estatística. Projeção da população em 2013. Rio de Janeiro: IBGE, 2016.

INPEV. Instituto Nacional de Processamento de Embalagens Vazias. Relatório de sustentabilidade de 2010. São Paulo: INPEV, 2010.

LACERDA, M. B. S.; OLIVEIRA, A. M.; CAMPOS, V. B.; MENESES JÚNIOR, J.C. Diagnóstico sócio-econômico dos agricultores e o impacto do programa bolsa família, Conceição - Paraíba - Brasil. Holos, v.26, v.1, 2010. DOI: http://doi.org/10.15628/holos.2010.336

LAKATOS, E. M.; MARCONI, M. A.. Fundamentos de metodologia científica. 6 ed. São Paulo: Atlas, 2007.

MAIA, D. C. S.. Remoção de $\mathrm{H}_{2} \mathrm{~S}$ e $\mathrm{CO}_{2}$ de biogás para utilização energética. Dissertação (Mestrado em Engenharia Química) - Universidade Estadual de Maringá, Maringá, 2011.

MARCATTO, C.. Educação ambiental: conceitos e princípios. Belo Horizonte: FEAM, 2002. 
MARTINS, A. L. L.; CARVALHO, J. J.; SANT'ANA, E. V. P.; PIRES, R. P.. Descrição da situação socioeconômica dos agricultores do Assentamento São João II. In: JORNADA DE INICIAÇÃO CIENTÍFICA E EXTENSÃO DO IFTO. Anais. Palmas, 2010.

MAZZER, C.; CAVALCANTI, O. A.. Introdução à gestão ambiental de resíduos. Infarma, v.16, n.11-12, p.67-77, 2004.

MENDES, A. G.; BOTEGA JUNIOR, C.; MARQUES, J. V.; SILVA, L. H.. Logística reversa de embalagens de produtos agrotóxicos. Monografia (Curso Técnico em Logística) Centro Estadual de Educação Tecnológica Paula Souza, Palmital, 2012.

MOUSINHO, P.. Glossário. In: TRIGUEIRO, A.. Meio ambiente no século 21. Rio de Janeiro: Sextante, 2003.

PAIM, R. O.; DALL'IGNA, S. F.. A importância da reforma agrária: diagnóstico do assentamento Congonhas - Abelardo Luz - SC/Brasil na perspectiva do desenvolvimento socioeconômico. In: SIMPÓSIO INTERNACIONAL DE GEOGRAFIA AGRÁRIA, 4. Anais. Niterói: UFF, 2009.

QUEIROGA, R. A.; SILVA, E. J. L.; FIGUEIREDO, M. V.; HAFLE, O. M.; FILHO, P. L.; PEREIRA JUNIOR, E. B.. Diagnóstico socioeconômico e ambiental do Assentamento Veneza, Município de Aparecida, Paraíba/PB. Agropecuária científica no Semiárido, v.10, n.4, p.5-14, 2014.

RAMALHO, A. R. S.. Diagnóstico ambiental e produtivo de comunidades rurais do município de una da região sul da Bahia. Dissertação (Mestrado em Ciências Ambientais) Universidade Estadual do Sudoeste da Bahia, Itapetinga, 2014.

RIBEIRO, D. V.; MORELLI, M. R.. Resíduos sólidos: problemas ou oportunidade?. Rio de Janeiro: Interciência, 2009.

ROSA, L. A. B.; GUIMARÃES, M. F.. Diagnóstico socioeconômico em assentamentos rurais no município de Tamarana - PR. Semina: Ciências Agrárias, Londrina, v.32, n.3, p.809-828, 2011. DOI: http://doi.org/10.5433/1679$\underline{0359.2011 v 32 n 3 p 809}$
SALGADO, R. V.. Os assentamentos rurais vinculados ao movimento dos trabalhadores sem-terra e a saúde pública: uma análise da produção bibliográfica nacional. Monografia (Especialização em Saúde Pública) - Universidade Federal do Rio Grande do Sul, Porto Alegre, 2012.

SANGALLI, A. R.. Assentamento Lagoa Grande, em Dourados, MS: aspectos socioeconômicos, limitações e potencialidades para o seu desenvolvimento. Dissertação (Mestrado em Ciências Contábeis e Economia) Universidade Federal da Grande Dourados, Dourados, 2013.

SANTANA, E. P. V. R. S.; OLIVEIRA, A. R.; MAIA E OLIVEIRA, F. J.. Diagnóstico sócio-econômico da comunidade Pindoba, Município de Areia-PB. Revista Verde, Mossoró, v.3, n.4, p.46-62, 2008.

SANTOS, G. G. D.. Análise e perspectivas de alternativas de destinação dos resíduos sólidos urbanos: o caso da incineração e da disposição em aterros. Dissertação (Mestrado em Planejamento Energético) - Universidade Federal do Rio de Janeiro, Rio de Janeiro, 2011.

SCHALCH, V.; LEITE, W. C. A.; FERNANDES JUNIOR, J. L.; CASTRO, M. C. A. A.. Gestão e Gerenciamento dos Resíduos Sólidos. São Carlos: USP, 2002.

SIMONATO, D. C.; FIGUEIREDO, R. A.; DORNFELD, C. B.; DOURADO, R.. Condições socioeconômicas e qualidade de vida de um assentamento rural no noroeste paulista, Ilha Solteira/SP. Retratos de Assentamentos, v.17, n.2, 2014.

SIQUEIRA, A.. Resíduos sólidos: da classificação à disposição final. Revista Fármacos \& Medicamentos, Viçosa, p.10-16, 2001.

SOUSA, P. R.. ICMS ecológico como instrumento de gestão participativa de resíduos sólidos no assentamento rural sítio, Palmas/TO. Dissertação (Mestrado em Engenharia Ambiental) - Universidade Federal do Tocantins, Palmas, 2015.

TENÓRIO, J. A. S.; ESPINOSA, D. C. R.. Controle Ambiental de Resíduos. In: PHILIPPI JUNIOR, A.; ROMÉRO, M. A.; BRUNA, G. C.. Curso de Gestão Ambiental. Barueri: Manole, 2004. 